\title{
Classical, phenomenological analysis of the kinetics of reactions at the gas-exposed surface of mixed ionic electronic conductors
}

\author{
David S. Mebane • Meilin Liu
}

Published online: 8 June 2006

(C) Springer-Verlag 2006

The online version of the original article can be found at http://dx.doi. org/10.1007/s10008-005-0144-9.

D. S. Mebane $\cdot$ M. Liu $(\square)$

School of Materials Science and Engineering,

Georgia Institute of Technology,

Atlanta, GA 30332-0245, USA

e-mail: meilin.liu@mse.gatech.edu
Unfortunately, there were several errors published in Eq. 22. The correct version is:

$$
r_{3}=k_{3}^{0}\left[\begin{array}{l}
\frac{c_{v} \theta}{c_{v, 0} \theta_{0}} \exp \left(\frac{\alpha_{3} F \Delta \chi}{R T}\right) \\
-\frac{c_{h}(1-\theta)}{c_{h, 0}\left(1-\theta_{0}\right)} \exp \left(\frac{-\left(1-\alpha_{3}\right) F \Delta \chi}{R T}\right)
\end{array}\right]
$$

